\title{
The changing patterns of cropland conversion to built-up land in China from 1987 to 2010
}

\author{
JU Hongrun ${ }^{1,2,3,4}$, ZHANG Zengxiang ${ }^{1}$, ZHAO Xiaoli ${ }^{1}$, WANG Xiao ${ }^{1}$, WU Wenbin ${ }^{5}$, \\ YI Ling ${ }^{1}$, WEN Qingke ${ }^{1}$, LIU Fang ${ }^{1}$, XU Jinyong ${ }^{1}$, HU Shunguang ${ }^{1},{ }^{*}$ ZUO Lijun ${ }^{1}$ \\ 1. Institute of Remote Sensing and Digital Earth, CAS, Beijing 100101, China; \\ 2. School of Tourism and Geography Science, Qingdao University, Qingdao 266071, Shandong, China; \\ 3. Department of Geography, University of California Santa Barbara, Santa Barbara, CA 93106, USA; \\ 4. University of Chinese Academy of Sciences, Beijing 100049, China; \\ 5. Key Laboratory of Agri-informatics, Ministry of Agriculture/Institute of Agricultural Resources and Regional \\ Planning, Chinese Academy of Agricultural Sciences, Beijing 100081, China
}

\begin{abstract}
Over the past few decades, built-up land in China has increasingly expanded with rapid urbanization, industrialization and rural settlements construction. The expansions encroached upon a large amount of cropland, placing great challenges on national food security. Although the impacts of urban expansion on cropland have been intensively illustrated, few attentions have been paid to differentiating the effects of growing urban areas, rural settlements, and industrial/transportation land. To fill this gap and offer comprehensive implications on framing policies for cropland protection, this study investigates and compares the spatio-temporal patterns of cropland conversion to urban areas, rural settlements, and industrial/transportation land from 1987 to 2010 , based on land use maps interpreted from remote sensing imagery. Five indicators were developed to analyze the impacts of built-up land expansion on cropland in China. We find that $42,822 \mathrm{~km}^{2}$ of cropland were converted into built-up land in China, accounting for $43.8 \%$ of total cropland loss during 1987-2010. Urban growth showed a greater impact on cropland loss than the expansion of rural settlements and the expansion of industrial/transportation land after 2000. The contribution of rural settlement expansion decreased; however, rural settlement saw the highest percentage of traditional cropland loss which is generally in high quality. The contribution of industrial/transportation land expansion increased dramatically and was mainly distributed in major food production regions. These changes were closely related to the economic restructuring, urban-rural transformation and government policies in China. Future cropland conservation should focus on not only finding a reasonable urbanization mode, but also solving the "hollowing village" problem and balancing the industrial transformations.
\end{abstract}

Keywords: cropland loss; urban growth; rural settlement; industrial land; transportation land; China

Received: 2017-06-30 Accepted: 2017-09-12

Foundation: National Major Science and Technology Program for Water Pollution Control and Treatment, No.2017ZX07101001

Author: Ju Hongrun (1990-), PhD, specialized in land use and GIS. E-mail: juhr@radi.ac.cn

*Corresponding author: Zuo Lijun, Associate Professor, E-mail: zuolj@radi.ac.cn 


\section{Introduction}

As the largest developing country in the world, China has experienced rapid economic development and broad scale urbanization and industrialization over the last decades, especially since the implementation of the reform and opening-up policy in 1978 (Longley, 2002). Along with these changes, land resources and the structure of land use in China have undergone profound changes. Perhaps the most notable land use change is the loss of large areas of cropland. The fast decline of cropland is due to the combined effects of rapid economic development, population growth, urbanization, agricultural restructuring, ecological policies, natural disasters and land degradation (Yang and Li, 2000; Ding, 2003; Tan et al., 2005). Among these factors, the demand for built-up land has placed growing pressure on the remaining available cropland resources. According to monitoring data from the Ministry of Land and Resources of China, the proportion of cropland lost to built-up land among the total cropland loss of China continuously increased in the 2000s. The expansion of built-up land also affected the quality of cropland in China due to the fact that cropland located at the urban and rural settlement fringes was generally in good condition and so could produce more food. According to a quality grade survey of cropland in China, the average quality grade of the lost cropland was 8.60, while that of newly added cropland was 9.88 in 2014 (quality grade 1 being the best quality and 15 the worst). The quick depletion and degradation of agricultural land resources is intrinsically linked to food insecurity, as well as to the livelihoods of millions of rural people across the country (Qin, 2010; Liu et al., 2015; d'Amour et al., 2017).

With its rapid economic development, China has experienced a rate of urban growth almost unparalleled in history. In 2011, the proportion of China's population living in urban areas reached $51.27 \%$ surpassing the agricultural population (NBSC, 2011). The conflict between the loss of arable land and urban development has attracted the special attention of many scholars worldwide (Anderson and Yang, 1998; Boland, 2000; She and Xie, 2000; Tania et al., 2001; Cai et al., 2002). In previous research, urban land was usually defined by impervious surfaces and other manifestation of the built environment (Seto et al., 2011), including both settlements and industrial/transportation land, as these classes are easy to extract from satellite images with automatic classification methods (Yeh and Li, 1999; Seto et al., 2011; Pandey and Seto, 2015). Industrial land is that used for the manufacturing and processing of commodities, while transportation is land in roads, pipelines, airports, railways and transportation storage facilities such as warehouses and shipping yards. With the further rapid development of industrialization and the movement of industries from the coastal cities and regions to the vast areas of inland China, more land will be needed by factories, quarries, mining, oil-field development and transportation. The industrial/transportation land expansion could become more significant drivers of cropland loss. It is worthwhile investigating the patterns of cropland lost to urban areas and to industrial/transportation land separately, before cropland protection strategies are designed and proposed.

When the increasing urban-rural disparities began to endanger socioeconomic stability, the Chinese government began to promote rural development by creating policies that favored rural areas to intensify the mutual linkages between cities and the countryside (Tu and Long, 2017). The rural collectives and their members have strong incentives to engage in farmland conversion activities in order to capture a share of profits from land conversion (Wang and 
Scott, 2008). Moreover, croplands in rural areas are always close to rural settlements in China (Xie et al., 2017), highlighting the potential vulnerability of agricultural land in rural areas to the expansion of rural settlements. Indeed, more cultivated land in southern Jiangsu was converted to rural settlements than to urban areas during 1990-2006 (Long et al., 2009; Liu et al., 2010). How these different types of built-up land place pressure on cropland is a question worth answering for the sake of framing more specific land management policies.

In this research, we investigated how the expansion of the three different built-up land types (urban, rural settlement, and industrial/transportation land) encroached on China's cropland from 1987 to 2010. Based on land use change data visually interpreted from remote sensing images, we illustrated the spatio-temporal patterns of the speed and the structure of cropland conversion to built-up land. We further quantitatively measured the influence of different built-up land on cropland loss from three aspects: the contribution of built-up land expansion to cropland loss, the dependence of built-up land expansion on cropland loss and the conversion's impacts on cropland quality. Finally, we discussed the drivers of the cropland conversion to built-up land and the implications on future cropland use. The research on investigating the individual effect of different types of built-up land on cropland loss is of great importance, since it helps understand the explicit drivers of massive cropland loss. By comparing the patterns of the different kinds of conversion and exploring the embodied drivers, we may highlight the risks of cropland loss in the future and develop precise suggestions on protecting cropland from this type of land use change.

\section{Data and methods}

\subsection{Land use data}

The spatio-temporal data revealing cropland lost to built-up land were obtained from the China Land Use Dataset at 1:100,000 scale established by the Chinese Academy of Sciences. It was visually interpreted by experts using medium resolution satellite images including Landsat MSS/TM/ETM, the China-Brazil Earth Resources Satellite (CBERS) and HJ-1A from the late 1980s (In the remainder of this paper, the year of 1987 was used to represent the period of the late 1980s, because images obtained in 1987 were the major sources for the land use interpretation for this period), 1995, 2000, 2005 and 2010. Landsat data were the main data source, and CBERS and HJ data were only used where no qualified or cloud free Landsat data were available. Field investigation was applied to verify the accuracy of the dataset, and the overall classification accuracy was above $90 \%$ (Zhang et al., 2014). The built-up land and cropland data used in this study were resampled to a raster format with a spatial resolution of $100 \mathrm{~m}$. It was converted from the original vector format by attributing each grid cell to the land type with the largest area within the cell.

A hierarchical land use classification system with six first level types and 25 second level types was adopted. The first level types included cropland, woodland, grassland, water bodies, built-up land and unused land. The cropland comprised two second level types of paddy and dry land, while the built-up land comprised three second level types of urban, rural settlement and industrial/transportation land. The cropland in this database included permanently cultivated land, newly cultivated land, fallow, and grassland farming with crop rotation land. It also included intercropping land such as crop-fruit, crop-mulberry, and 
crop-forest land in which the crop was the dominant species (Liu et al., 2005). Urban referred to land used for urban settlement, with a largely continuous area covered by urban construction and city facilities. Rural settlement referred to land used for village settlements, while industrial/transportation land referred to land used for factories, quarries, mining, oil-fields outside cities and land for transportation uses, such as railroads, pipelines, highways and airports (Zhang et al., 2014).

\subsection{Methods}

We developed five indicators to understand the process of the conversion from cropland to built-up land. We illustrated the spatio-temporal patterns of the conversion from two aspects: the speed of cropland lost to built-up land $\left(S C B_{i}\right)$ and the proportion of cropland loss to each type of built-up land in total area of cropland converted into built-up land $\left(P C B_{i}\right)$. The impacts of built-up land expansion on cropland loss were measured by three indicators: the contribution of built-up land expansion to cropland loss $\left(\right.$ Ccrop $\left._{i}\right)$, the dependence of built-up land expansion on cropland loss $\left(\right.$ Dcrop $\left._{i}\right)$, and the impact of built-up land expansion on cropland quality $\left(\right.$ Tcrop $\left._{i}\right)$. The relationships between these indicators are shown in Figure 1. Databases of built-up land and cropland for 1987, 1995, 2000, 2005 and 2010 were created in ESRI's ArcView geographic information system (GIS) software to compute these indicators.

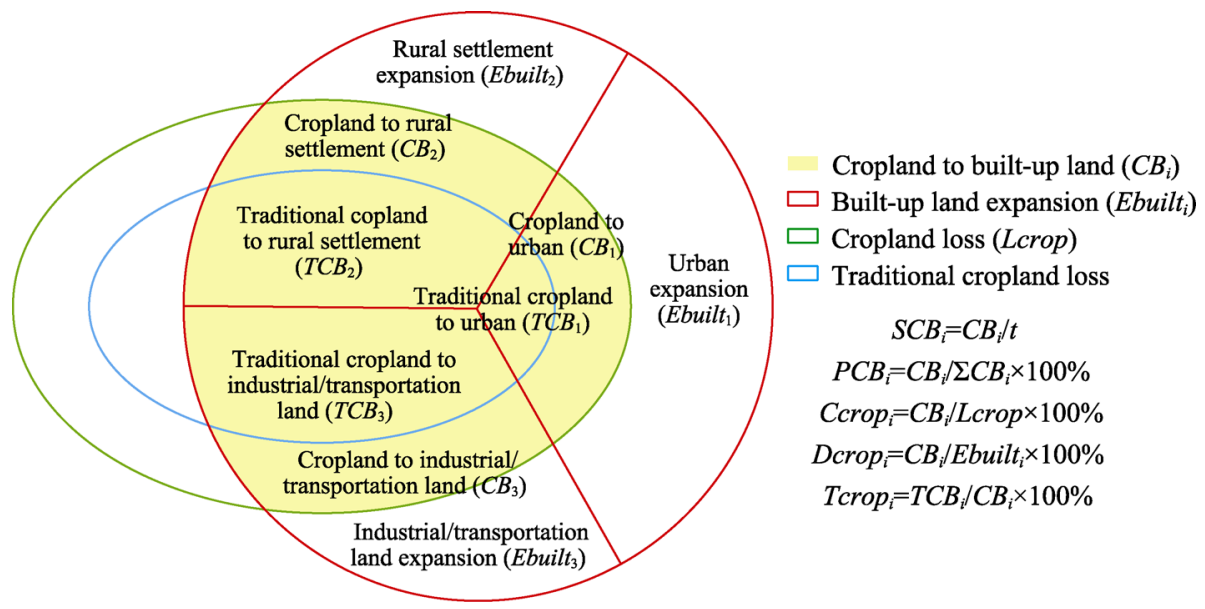

Figure 1 The relationship between built-up land expansion and cropland loss

To explicitly describe the spatial patterns of cropland conversion to built-up land and the impacts of this conversion on cropland loss, we adopted the "comprehensive agricultural zonation of China" to analyze the spatial variation by regions (NCAR, 1981). The division of the regions is based primarily on their agriculture production and geographic features. These regions include Northeast agriculture and forestry region; Inner Mongolia and along the Great Wall pastoral, agriculture and forestry region; Huang-Huai-Hai Plain agriculture region; Loess Plateau agriculture, forestry and pastoral region; Middle-Lower Yangtze River agriculture, forestry and aquaculture region; Southwest agriculture and forestry region; South China agriculture, forestry and tropical crops region; Gansu-Xinjiang agriculture, forestry and pastoral region; and Qinghai-Tibet Plateau pastoral, agriculture and forestry region (Figure 2). Among these regions, Qinghai-Tibet region has the smallest amount of cropland which was distributed sparsely. The Northeast region, the Huang-Huai-Hai Plain region, the 
north part of the Middle-Lower Yangtze River region and the central part of the Southwest region has a large amount of cropland clustered in a large continuous area. By contrast, the cropland in southern part of the Southwest region, the southern part of the Middle-Lower Yangtze River region, and the South China region is fragmentedly distributed.

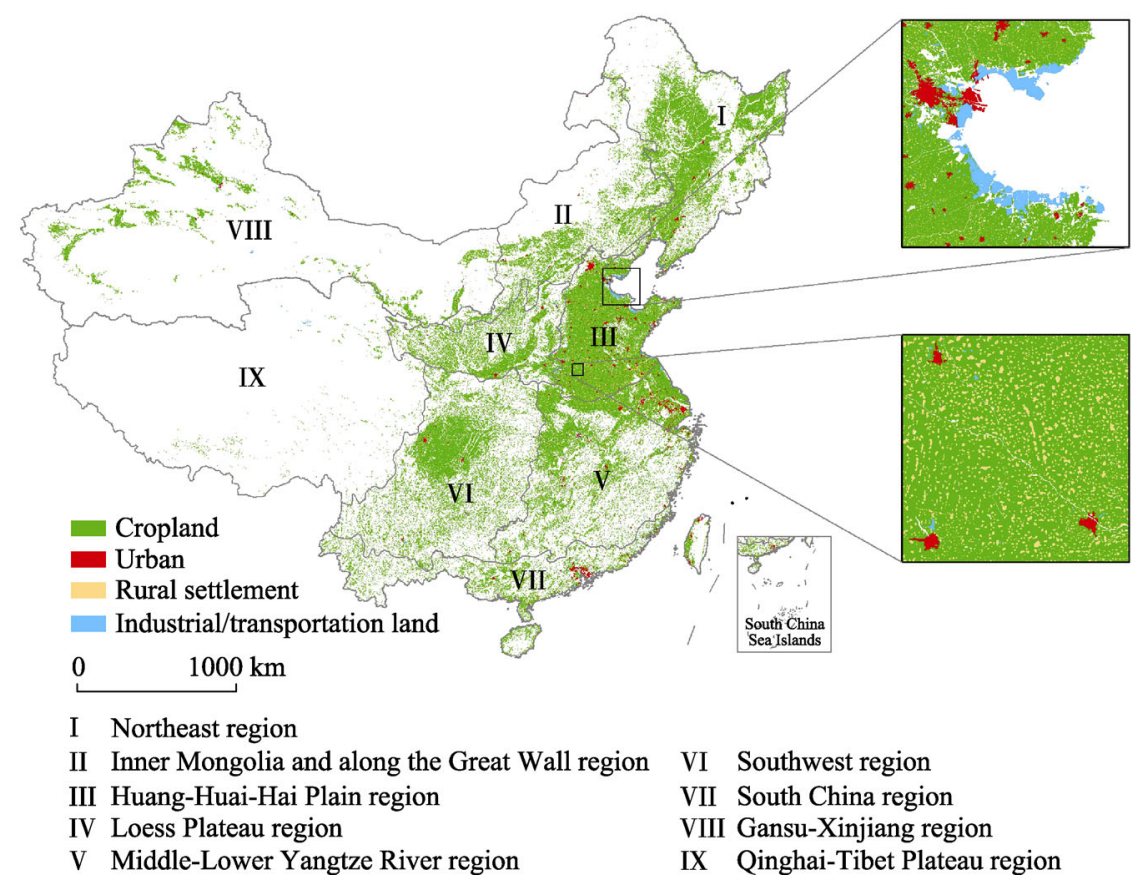

Figure 2 Distribution of cropland and built-up land and the agricultural regions in China in 2010

2.2.1 Methodology for measuring the patterns of cropland lost to built-up land

For temporal patterns, we used the annual area of cropland converted into built-up land (the speed of conversion) to illustrate the quantity, while the percentage of cropland lost to each built-up land type in the cropland lost to total built-up land was used to measure the proportion change.

The speed of cropland lost to built-up land $\left(S C B_{i}\right)$ (Figure 1) was calculated as follows:

$$
S C B_{i}=C B_{i} / t
$$

where $C B_{i}$ represents the area of cropland lost to built-up land type $i$. The area of cropland lost to built-up land was obtained by extracting the grids of cropland in the early period and the built-up land in the later period using GIS overlay analysis. Built-up land type $i$ includes urban, rural settlement, industrial/transportation land and built-up land. $S C B_{i}$ was calculated for four periods: 1987-1995, 1995-2000, 2000-2005, and 2005-2010. The value of $t$ was 8 for the period of 1987-1995 and was 5 for the other periods. The larger the $S C B_{i}$, the faster the built-up land use type $i$ encroached on the cropland.

The proportion of cropland lost to each built-up land type in cropland lost to total built-up land $\left(P C B_{i}\right)$ (Figure 1) was calculated as follows:

$$
P C B_{i}=C B_{i} / \sum C B_{i} \times 100 \%
$$

where $C B_{i}$ means the same as in equation 1. Built-up land type $i$ includes urban, rural settlement and industrial/transportation land. $P C B_{i}$ was calculated for four periods: 
1987-1995, 1995-2000, 2000-2005, and 2005-2010. The larger the $P C B_{i}$, the more built-up land type $i$ contributes to cropland loss.

For spatial pattern, we used conversion area from cropland to built-up land in each grid cell to illustrate the quantity, and the dominant built-up land type in each grid to illustrate the proportion. We employed a gridded zonal model with a $5-\mathrm{km}$ resolution to facilitate the visualization of the land use change (Zuo et al., 2014). The map produced a spatial distribution of the two indicators, from which the spatial patterns of cropland lost to built-up land could be seen. First, we generated a standard grid frame in vector format using the FISHNET module in the ArcGIS software over the study area. Each cell of the grid was 5 $\mathrm{km} \times 5 \mathrm{~km}$. Then, we used the $25-\mathrm{km}^{2}$ grid to intersect with the patches from the $100 \mathrm{~m}$ data to obtain five types of the $25-\mathrm{km}^{2}$ gridded zonal values: area of cropland lost to built-up land, area of cropland lost to urban, area of cropland lost to rural settlement, area of cropland lost to industrial/transportation land and the dominant built-up land use type. Since the spatial pattern changed a great deal before and after 2000, we did the spatial analyses for two periods: $1987-2000$ and 2000-2010.

2.2.2 Methodology for measuring the impacts of built-up land expansion on cropland loss

We used the percentage of cropland lost to built-up land in the total cropland loss area to indicate the contribution of built-up land expansion to cropland loss $\left(\right.$ Ccrop $\left._{i}\right)$ (Figure 1), which was defined as:

$$
\text { Ccrop }_{i}=C B_{i} / \text { Lcrop } \times 100 \%
$$

where Lcrop represents the area of cropland loss. $C B_{i}$, built-up land type $i$ means the same as in equation 1. A larger value of this index indicates a more critical impact of built-up land expansion on the cropland loss.

We took the percentage of cropland lost to built-up land in the total built-up land expansion area as an indicator illustrating the dependence of built-up land expansion on cropland loss $\left(\right.$ Dcrop $\left._{i}\right)$ (Figure 1), which was defined as:

$$
\text { Dcrop }_{i}=C B_{i} / \text { Ebuilt }_{i} \times 100 \%
$$

where Ebuilt $t_{i}$ represents the expansion area of built-up land type $i$ during the period $j . C B_{i}$ and built-up land type $i$ mean the same as in equation 1. A larger Dcrop value indicates built-up land expansion relies more on the cropland as its land source.

We used the percentage of traditional cropland in the cropland lost to built-up land as the indicator illustrating the impacts on cropland quality. Here, we defined traditional cropland as the cropland that has existed since 1987. The existing croplands in China are generally in more favorable condition for food production than the newly claimed and more marginal cropland (d'Amour et al., 2017). The percentage of traditional cropland in cropland lost to built-up land (Tcrop $)_{i}$ ) (Figure 1) was calculated as follows:

$$
\text { Tcrop }_{i}=T C B_{i} / C B_{i} \times 100 \%
$$

where $T C B_{i}$ represents the area of traditional cropland lost to built-up land type $i$ and $C B_{i}$ means the same as in equation 1. Here, Tcrop was calculated for four periods of 1995-2000, 2000-2005, 2005-2010, and the whole period of 1987-2010 (1987-1995 was not included in this analysis because this was the base period). A larger Tcrop value indicates built-up land expansion encroaches upon more traditional cropland. 


\section{Results}

\subsection{Spatio-temporal patterns of cropland lost to built-up land}

During 1987 to 2010 , a total of $42822 \mathrm{~km}^{2}$ of cropland was converted into built-up land in China (Table 1). The rate of cropland loss to overall built-up land fell greatly from 1492.81 $\mathrm{km}^{2} / \mathrm{yr}$ in $1987-1995$ to $833.32 \mathrm{~km}^{2} / \mathrm{yr}$ in $1995-2000$; however, it grew dramatically after 2000 and reached $2827.41 \mathrm{~km}^{2} / \mathrm{yr}$ in $2005-2010$. The rate of cropland lost to urban land first decreased in 1995-2000, and then peaked at $1290.22 \mathrm{~km}^{2} / \mathrm{yr}$ in $2000-2005$. For rural settlement, the speed of cropland lost was stable at about $700 \mathrm{~km}^{2} / \mathrm{yr}$ except for falling during 1995-2000. The speed of cropland loss to industrial/transportation land increased from $120.76 \mathrm{~km}^{2} / \mathrm{yr}$ in the late $1980 \mathrm{~s}-1995$ to $931.60 \mathrm{~km}^{2} / \mathrm{yr}$ in $2000-2005$. Urban had the highest speed of encroaching upon cropland among the three types of built-up land after 2000. The speed of industrial/transportation land encroaching upon cropland was the lowest of the three types, however, it exceeded the rate of loss to rural settlement in the last period (Figure 3).

Table 1 The area of cropland converted into built-up land of China during 1987-2010

\begin{tabular}{lccccc}
\hline Cropland to built-up land $\left(\mathrm{km}^{2}\right)$ & $1987-1995$ & $1995-2000$ & $2000-2005$ & $2005-2010$ & $1987-2010$ \\
\hline Urban & 5440 & 1265 & 6451 & 5945 & 19101 \\
Rural settlement & 5536 & 2184 & 3609 & 3534 & 14863 \\
Industrial/transportation land & 966 & 718 & 2517 & 4658 & 8859 \\
Total & 11942 & 4167 & 12576 & 14137 & 42822 \\
\hline
\end{tabular}

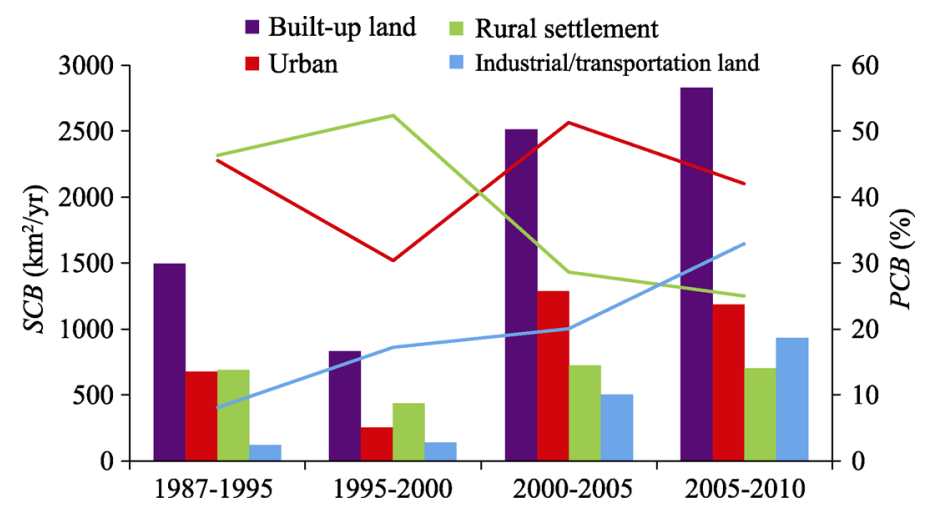

Figure 3 Temporal changes of $S C B$ (the speed of cropland lost to built-up land) and $P C B$ (the proportion of cropland lost to each built-up land type in the cropland lost to total built-up land) in China from 1987 to 2010

Over the entire period, urban land encroached most on cropland, accounting for $44.6 \%$ of the total cropland lost to built-up land, while rural settlement and industrial/transportation land accounted for $34.7 \%$ and $20.7 \%$, respectively. However, the contribution of the different built-up land types changed over time. The percentage of cropland lost to urban land decreased to $30.4 \%$ in $1995-2000$, the lowest in all four periods, and then peaked at $51.3 \%$ in 2000-2005. The percentage of loss to rural settlement saw a slight increase and peaked at $52.4 \%$ in $1995-2000$; followed by a decrease, ending up at $25.0 \%$ in $2005-2010$. The contribution of industrial/transportation land became increasingly larger, as its percentage went from $8.1 \%$ to $33.0 \%$ during the entire period (Figure 3 ).

The spatial pattern of cropland loss to built-up land changed significantly before and after 
2000. In 1987-2000, this kind of conversion clustered in the west of the Huang-Huai-Hai Plain region, the northeast of the Middle-Lower Yangtze River region, the east of the South China region, the middle of the Southwest region, and the south of the Loess Plateau region. By contrast, the conversion in the other regions was scattered. In 2000-2010, the distribution of cropland lost to built-up land was more widespread and more evenly distributed across the regions in the east and south of China. Most regions in China showed an increase in the area of cropland lost to built-up land, except for Gansu-Xinjiang and Qinghai-Tibet Plateau (Figures $4 \mathrm{a}$ and 4b).

The distribution of cropland lost to urban land was near the city fringes and scattered in space. In 2000-2010, urban land expanded into cropland more intensively all over the country with several obvious clusters in Beijing, Tianjin, the Yangtze River Delta Economic Zone and the Pearl River Delta Economic Zone (Figures 4c and 4d). In contrast, cropland lost to rural settlement was distributed more widely. During 1987-2000, rural settlement encroached upon a large amount of cropland in the Huang-Huai-Hai Plain region and the Middle-Lower Yangtze River region, while in 2000-2010, the total area of cropland occupied by rural settlement decreased, and the Huang-Huai-Hai Plain region experienced the largest decrease. However, other regions including Middle-Lower Yangtze River region, Southwest region, Northeast region and Inner Mongolia and along the Great Wall region saw an increase in the loss of cropland to rural settlement (Figures $4 \mathrm{e}$ and $4 \mathrm{f}$ ). The spatial distribution
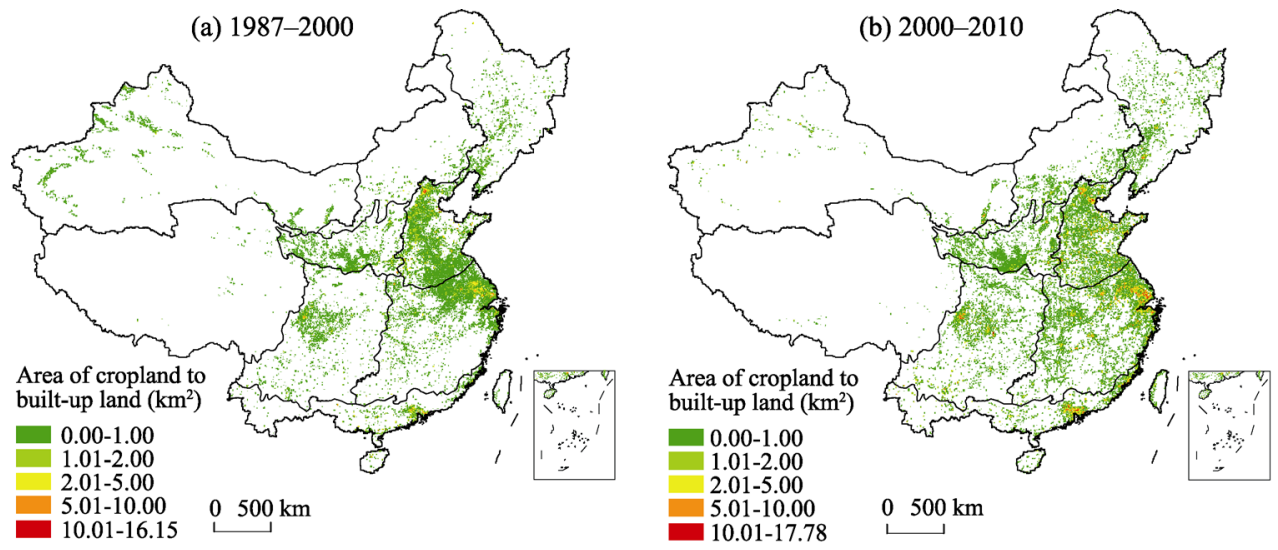

(c) $1987-2000$

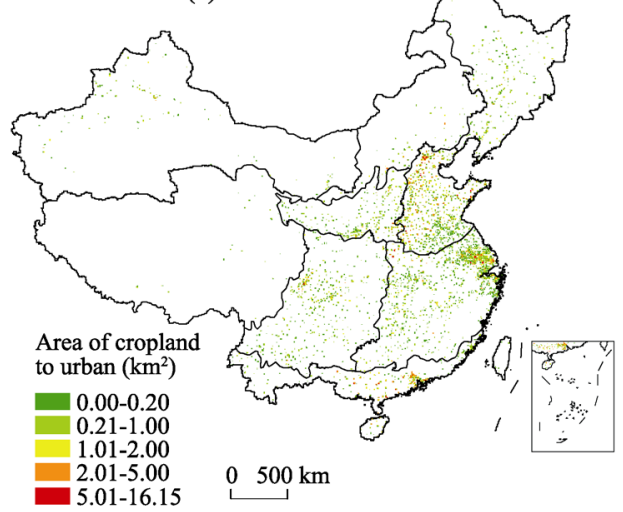

(d) $2000-2010$

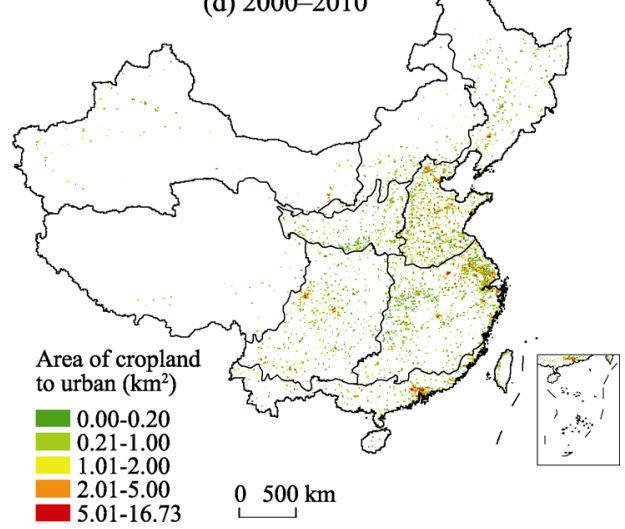



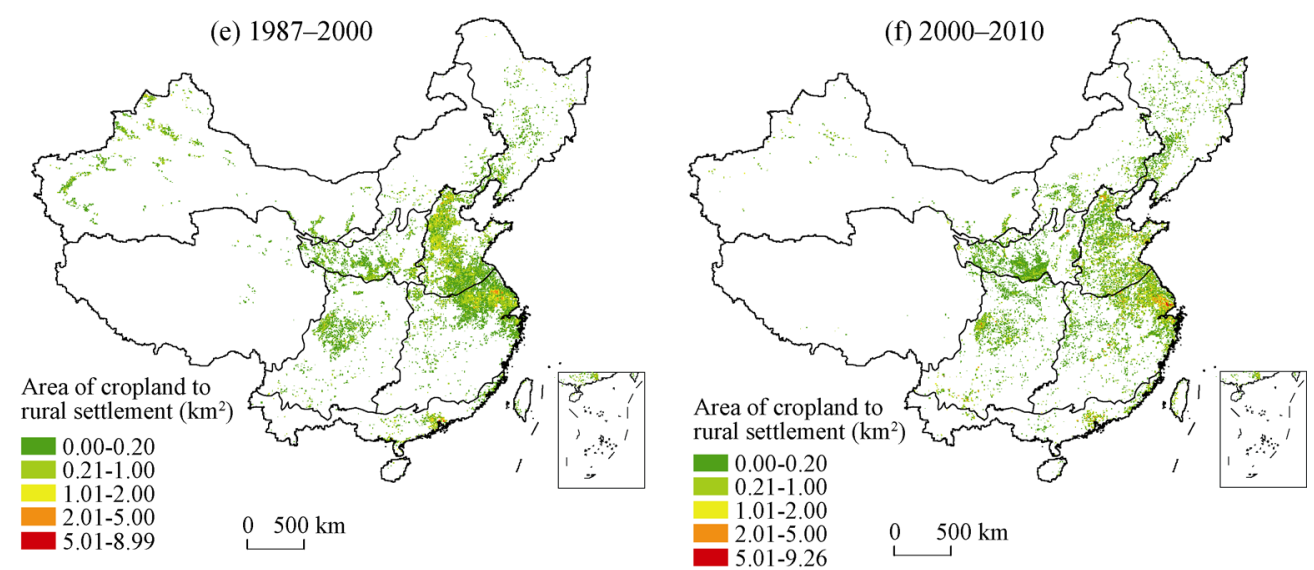

(g) $1987-2000$
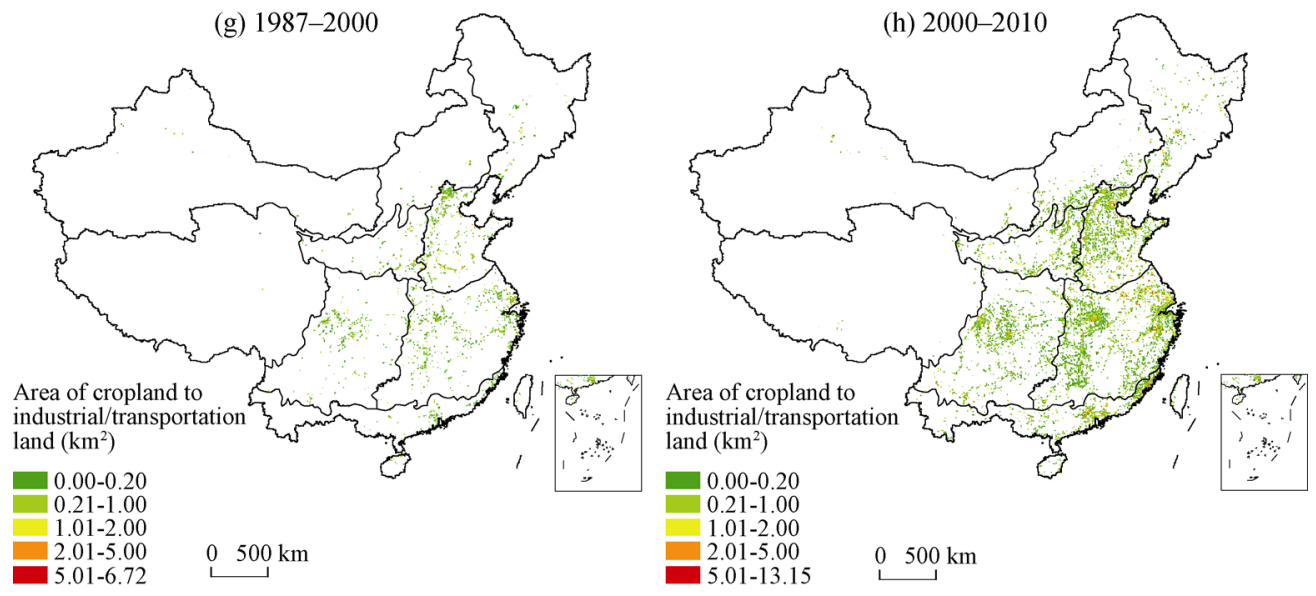

Figure 4 Spatial patterns of areas of cropland lost to built-up land of China in $5 \mathrm{~km} \times 5 \mathrm{~km}$ grids

of cropland loss to industrial/transportation land was quite scattered during 1987 to 2000, and it caused the least cropland loss in all regions. In 2000-2010, however, the industrial/ transportation land expanded significantly and occupied a large amount of cropland, especially in Middle-Lower Yangtze River region, South China region, Huang-Huai-Hai Plain region and Southwest region (Figures $4 \mathrm{~g}$ and $4 \mathrm{~h}$ ).

The dominant type of each grid indicates the leading contributor to cropland loss. In China, the loss of cropland to rural settlements was the dominant type in most areas where the conversion from cropland to built-up land happened in both periods. During 1987-2000, 72.6\% of the grid cells with cropland lost to built-up land were dominated by rural settlement expansion, which were mainly in the west of the Huang-Huai-Hai Plain region and the northeast of the Middle-Lower Yangtze River region (Figure 5a). This loss fell to 45.8\% during 2000-2010, accompanied by a dramatic increase in the loss to industrial/transportation land (Figure $5 \mathrm{~b}$ ). The percentage of the grid cells with industrial/transportation land expansion as the dominant type increased dramatically from $6.9 \%$ in the early period to $32.2 \%$ in the later period. The percentage of grid cells dominated by cropland loss to urban expansion was relatively stable, $20.5 \%$ and $22.0 \%$ for the former and latter period, respectively. The cropland losses dominated by urban expansion were mainly concentrated in Beijing, Tianjin, the Yangtze River Delta Economic Zone and the Pearl River Delta Economic Zone. 


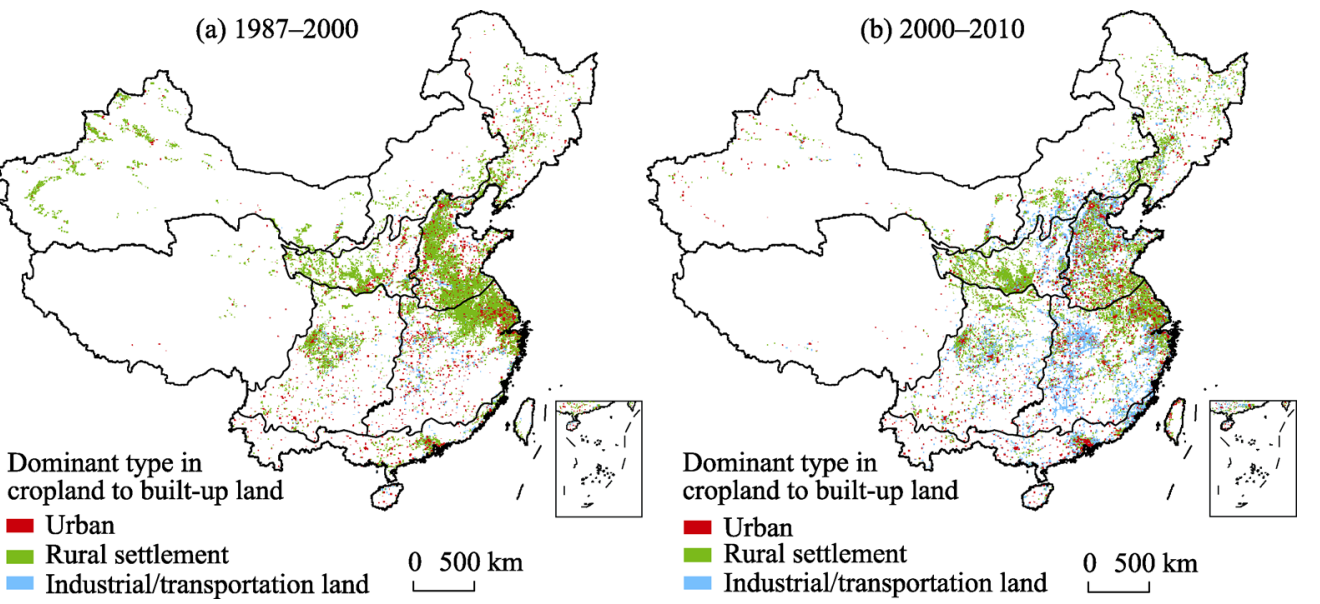

Figure 5 Spatial patterns of dominant types of cropland conversion to built-up land of China in $5 \mathrm{~km} \times 5 \mathrm{~km}$ grid cells

\subsection{Effects of built-up land expansion on cropland loss}

It was found that built-up land expansion explained $43.8 \%$ of the total cropland loss during 1987 and 2010 in China. However, this situation varied over time. Before 2000, only about $30 \%$ of the lost cropland was converted into built-up land; but this figure soared to $71.1 \%$ during 2005-2010. This indicates that built-up land has become an increasingly important factor in causing cropland loss. Among the three types of built-up land, the largest contributor to cropland loss changed from rural settlements before 2000 to urban land after the year 2000. The contribution of the industrial/transportation land expansion was the smallest at first; however, it grew sharply by more than 9 times and ended up as the second largest contributor to cropland loss after urban expansion in the last period (Figure 6a).
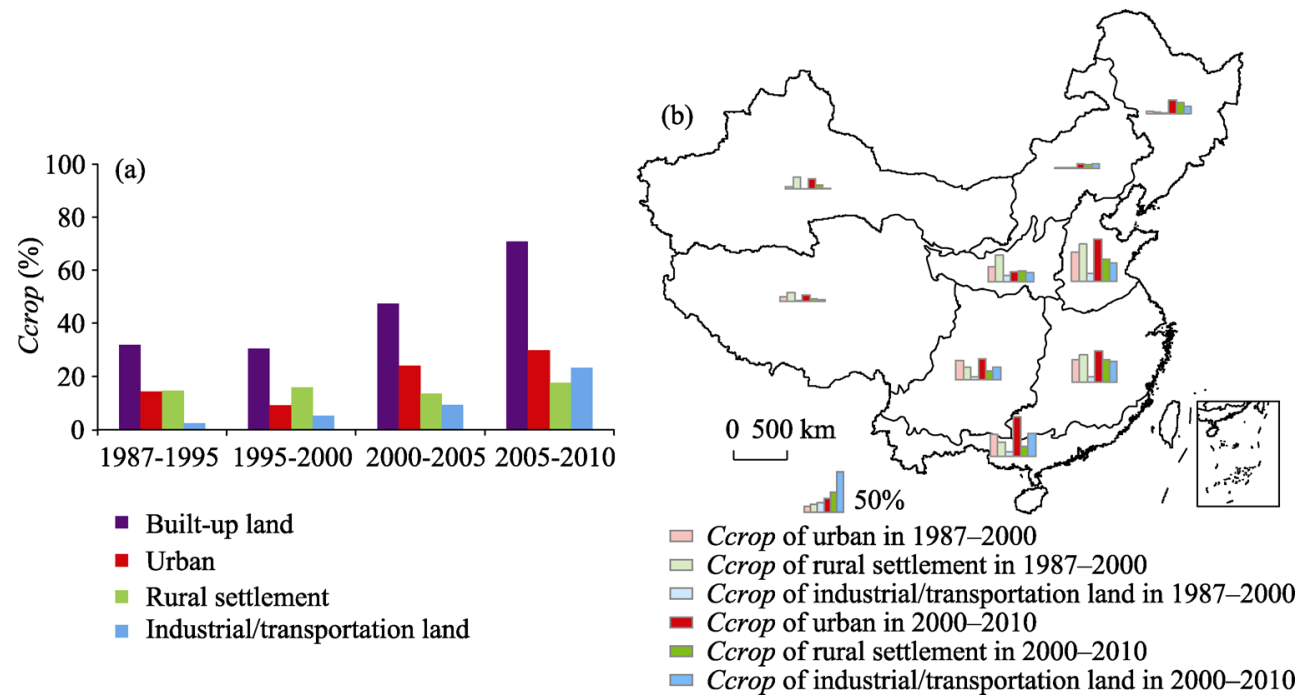

Figure 6 Spatio-temporal pattern of Ccrop in China (the contribution of built-up land expansion to cropland loss)

Spatially, during 1987-2000, built-up land expansion in the Huang-Huai-Hai Plain region 
had the largest impact on the cropland loss, followed by the Middle-Lower Yangtze River region. Both of these two regions are major food producing zones in China. In most regions, rural settlement had the largest contribution to the cropland loss; however, in the South China region and the Southwest region, urban was the type that encroached on the most cropland. During 2000-2010, urban became the type that caused the largest cropland loss in most regions except in the Loess Plateau region. Further, the effects of industrial/transportation land on cropland loss increased a great deal and even surpassed that of the loss to rural settlement in Inner Mongolia and along the Great Wall region, the Southwest region and the South China region (Figure 6b).

The expansion of built-up land in China during the period depended heavily on the availability for conversion of cropland. Most $(85.8 \%)$ of the built-up land expansion come from cropland loss, however, the percentage fell to $69.8 \%$ by 2010 . Among the different types of built-up land, rural settlement expansion depended mostly on cropland; more than $85 \%$ of rural settlement expansion comes from cropland loss for the whole period. The dependence of urban and industrial/transportation land expansion on cropland loss had similar temporal sequences, an increase during 1995-2000 and a decrease during 2000-2005. However, the dependence of urban expansion on cropland was much higher than that of industrial/transportation land (Figure 7a).
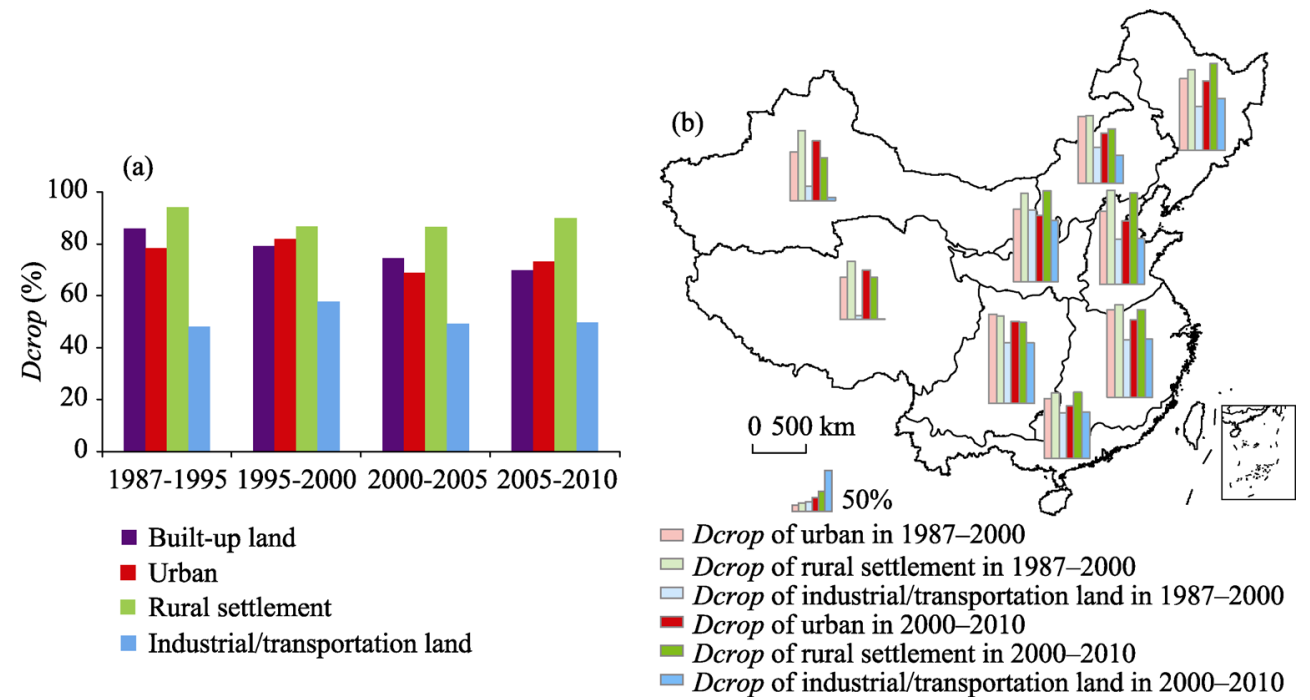

Figure 7 Spatio-temporal pattern of Dcrop in China (the dependence of built-up land expansion on cropland loss)

Spatially, croplands were the major source for built-up land expansion, especially to urban and rural settlement expansion. During 1987 and 2000, the percentage of new rural settlement changing from cropland was larger than that of urban in all regions except the Southwest region. During 2000-2010, proportionally less of the rural settlement expansion encroached onto cropland, except for the Northeast region, the Loess Plateau region and the South China region. Urban expansion also showed a lower percentage of encroachment into cropland in most regions. However, the Gansu-Xinjiang region and the Tibetan Plateau region experienced an increase in the percentage, which even surpassed that of rural settlement (Figure $7 b)$. 
Traditional cropland was usually of good quality and produced more food than newly reclaimed cropland in China, because most of the suitable land was already under intense, multi-cropping cultivation (d'Amour et al., 2017). It was found that $90.3 \%$ of the cropland occupied by the built-up land was traditional cropland for the whole period of study. In the early period (1995-2000), built-up land expansion consumed a smaller proportion of traditional cropland at $76.0 \%$. However, the proportion kept increasing and ended up at $88.5 \%$ in 2005-2010. This indicates that more and more built-up land expansion occupied traditional cropland of the best food production quality. Rural settlement expansion took the highest percentage of traditional cropland, followed by urban growth. Industrial/transportation land expansion consumed least traditional cropland (Figure 8a).
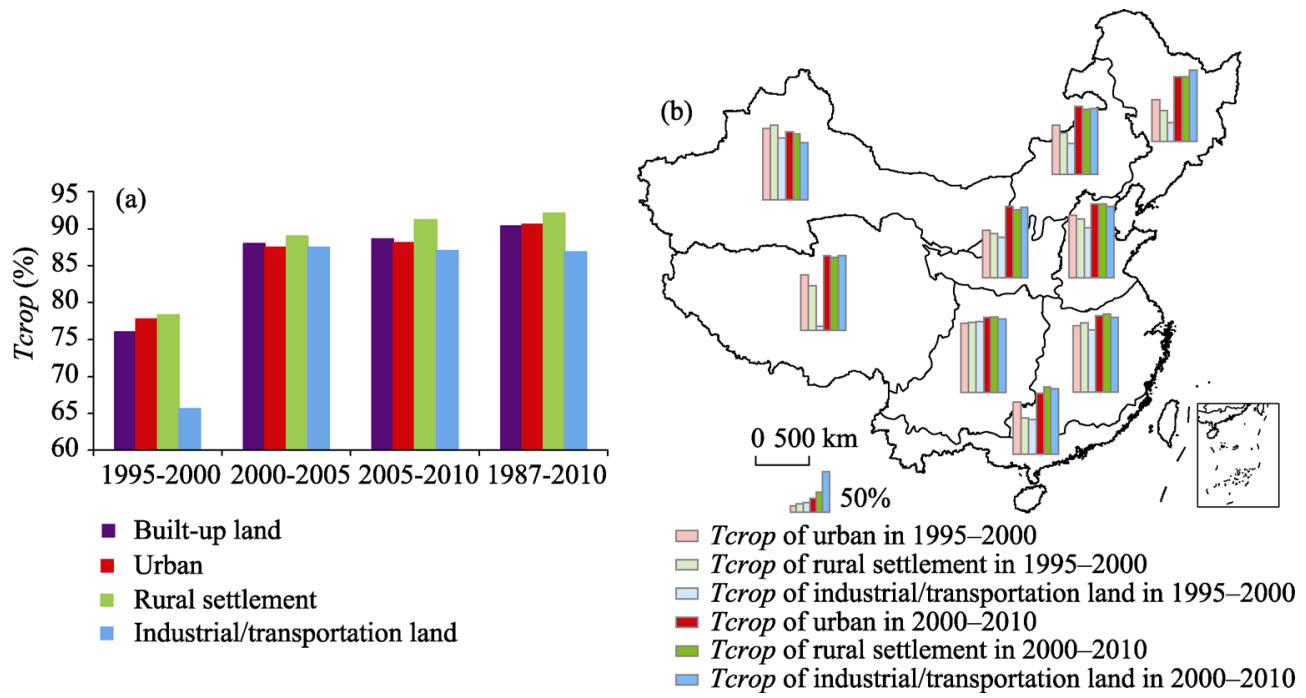

Figure 8 Spatio-temporal pattern of Tcrop (the percentage of traditional cropland in the cropland lost to built-up land)

Spatially, during 1995-2000, urban land use occupied a higher proportion of traditional cropland in most regions except the Middle-Lower Yangtze River region, the Southwest region and the Gansu-Xinjiang region. In 2000-2010, the proportion of traditional cropland in cropland lost to built-up land saw an obvious increase in all regions except the Gansu-Xinjiang region. During this period, rural settlements encroached on proportionally more traditional cropland in the Huang-Huai-Hai Plain region, the Middle-Lower Yangtze River region, the Southwest region and the South China region, where the cropland quality is generally higher than in other regions of the country. The Middle-Lower Yangtze River region had the largest proportion of traditional cropland lost to built-up land among all the regions in the later period (Figure $8 \mathrm{~b}$ ).

\section{Discussion}

\subsection{Drivers of cropland loss to built-up land}

Economic growth, represented by GDP growth, is recognized as the major driver of urban expansion in China (Liu et al., 2005; Seto et al., 2011), which in turn places great pressure on cropland. Therefore, the changes in annual GDP growth and its structure help to understand the patterns of cropland lost to built-up land. According to the data from NBSC 
(NBSC, 2011), the average annual GDP growth rate for China in 1987-1995 was 21.9\%, before it declined to $10.5 \%$ in 1995-2000. After 2000, the annual GDP growth rate gradually increased, ending up as $13.5 \%$ and $17.3 \%$ for the period of 2000-2005 and 2005-2010 respectively. Correspondingly, the cropland loss to built-up land also experienced a similar process; the annual area of cropland loss to built-up land bottomed out in 1995-2000, and increased afterward (Figure 3). Meanwhile, the contributions to GDP from different sectors changed over time. The percentage of GDP from agriculture continuously decreased from $22.9 \%$ in the period of $1987-1995$ to $10.1 \%$ in the period of $2005-2010$. This largely explains the decline of contributions from rural settlement to the cropland lost to built-up land, and the increasing contributions from urban and industrial/transportation land as a whole.

Population changes directly influence urbanization and urban land (Pacione, 2001), and population migration also drives urban and rural land expansion. In China, the total population increased at an annual rate of $0.92 \%$ from 1.08 billion in 1987 to 1.34 billion in 2010 . However, the changes of urban population and rural population were completely different. The average annual growth rate of the urban population was $3.92 \%$, while the agricultural population has been decreasing since 1996 (NBSC, 2011). Although rural settlement still saw an expansion after 2000 due to the "rural hollowing" problem ( $\mathrm{Li}$ et al., 2015), the percentage of rural settlement expansion among total built-up land expansion decreased, and in turn the percentage of cropland lost to rural settlement in the cropland lost to built-up land decreased greatly from $52.4 \%$ in $1995-2000$ to $25.0 \%$ in $2005-2010$ (Figure 3).

Policy and land management are the third kind of factor that drives the changes in the pattern of cropland loss to built-up land. Building industrial parks has spread overwhelmingly almost all over the country since China launched reform. These started in the coastal regions of China, but now are flourishing in the vast inland of China. Industrial/transportation land saw a dramatic expansion and was causing larger and larger amounts of cropland loss. Both the speed of cropland loss to industrial/transportation land and its percentage of total cropland lost to built-up land increased greatly. Moreover, with the planning of a medium and long term railway network proposed in 2004, high-speed railway construction promoted by the central government has accelerated transportation land expansion, as well.

Various factors have led to the expansion of built-up land, thus taking up productive cropland. However, positive land use management could slow down the loss of cropland ( $\mathrm{Li}$ et al., 2014). To protect the cropland from being encroached by built-up land, the State Council released Regulations for the Protection of Basic Agricultural Land (Jiben Nongtian Baohu Tiaoli) in 1994, and the Protection Rules of Basic Farmland (New Jiben Nongtian Baohu Tiaoli) in 1998. Additionally, a "requisition-compensation balance of arable land" policy was implemented in 1997. From our results, we can see the decline of the dependence of built-up land expansion on cropland conversion (Figure 7).

\subsection{Implications on future cropland use}

Cropland is the major source of land for built-up land expansion, since it is located nearby or surrounding settlements. China is undergoing a historic urban-rural transformation process and is anticipating a boom of new urbanization in the near future. Much land will be in demand, not only to accommodate the large and growing population, but also to support the 
development of various industries and to support infrastructure projects. d'Amour et al. (2017) projected that from 2000 to 2030 , one quarter of global cropland loss $\left(7.6 \times 10^{6} \mathrm{ha}\right)$ due to urban expansion that would occur in China. Therefore, cropland loss is a lasting problem worthy of attention. The combination of a growing urban population and a declining rural population with diminishing and more impacted farmland means that China's food security will be increasingly threatened.

As our results show, urban expansion has consumed the largest amount of cropland since 2000. Things might be getting even worse as China has shifted the urban development strategy from developing big cities as a priority to developing small towns or secondary cities. This may be a more land consuming mode of urbanization. Research indicates that if we had developed small towns as a priority during 1995-2000, there would be $9 \%$ more cropland lost to urban; and the additional cropland loss would be even larger $(29 \%)$ in 2000-2008 as the urbanization rate in this period was much higher (Deng et al., 2015).

For rural settlement expansion, although we measured a decreasing value of $P C B$ since the year 2000 and the rural population was migrating to cities, rural settlements continued to expand over the last 20 years. According to land use and population data (NBSC, 2011), the rural settlement use of land per capita increased from $151.95 \mathrm{~m}^{2}$ to $203.93 \mathrm{~m}^{2}$ during 1987-2010, which was considerably above the national standard of $150 \mathrm{~m}^{2}$ per capita (MCC, 1993). The "hollowing village" has become quite common in many areas of China, in which new houses are built at the fringes of rural towns and historical village centers are abandoned. Also, cropland encroachment by rural settlement was more likely to be into traditional and more fertile cropland (Figure 8). This further magnifies the pressure of rural settlement expansion on cropland and on the food supply.

Industrial/transportation land was the kind of built-up land taking up more and more cropland in the past. During 1990-2010, the railways, highways, inland waterways, civil aviation lines and pipelines increased by $0.58,2.9,0.14,4.46$ and 3.11 times, respectively (Jiao et al., 2016). This trend is more likely to continue into the near future. With the promotion of policies such as "Rise of Central China" and "Belt and Road Initiative", central and western regions of China are anticipated to see more economic growth, industrialization and an emphasis on transportation. Building industrial parks to collocate various factories and companies has already been quite common and will be more widely spread to many other parts of China. What's more, although high-speed roads and high-speed railway have been greatly developed in the last several years, airports are now only just starting to boom. As a result, transportation land expansion will continue to induce a large amount of cropland loss.

\section{Conclusions}

Based on land use data interpreted from remote sensing imagery, this study examined the spatio-temporal patterns of cropland lost to different types of built-up land in China during 1987-2010. In addition, the impacts of built-up land expansion on cropland loss were measured quantitatively. With the new knowledge, drivers of this conversion and implications on future cropland use were further analyzed.

Results showed that $42,822 \mathrm{~km}^{2}$ of cropland were converted into built-up land in China, accounting for $43.8 \%$ of total cropland loss during 1987-2010. Among the three types of built-up land, the contribution of rural settlement expansion to this kind of conversion de- 
creased, while that of industrial/transportation land expansion increased dramatically. The increment of cropland lost to industrial/transportation land mainly distributed in regions with high-quality cropland, such as the Middle-Lower Yangtze River region, the South China region, the Huang-Huai-Hai Plain region and the Southwest region. In addition, the built-up land expansion depended on cropland heavily. $85.8 \%$ of the built-up land expansion came from cropland in 1987-1995, however, the percentage fell down to $69.8 \%$ at last. Among the different types of built-up land, rural settlement expansion depended on cropland mostly and took up the highest proportion of traditional cropland, which placed great pressure on cropland quality.

The fast increase in economic activity and the large rural to urban transformation were the main driving forces of the cropland lost to built-up land. Policies to protect the cropland showed obvious effects in the period of 1995-2000, however, the booming industrial land construction and intensive expansion of small cities drove a massive conversion from cropland to built-up land afterwards. Our results suggest that other than urban expansion, rural settlement should be a focus when conserving cropland because of its widest distribution, greatest dependence on croplands when expanding, and the greatest impacts on high quality traditional cropland. In addition, industrial/transportation land has a high potential to threaten the cropland in the future because of the undergoing transformation of industries from coastal region to inland China. Comprehensive regulations on the development of built-up land are essential to cropland conservation.

Our research offers evidences that the expansion of different built-up land types places distinguishing impacts on cropland in terms of quantity and quality, suggesting the importance of regulations on the development of rural settlements and industrial/transportation land when cropland protection policies are framed. For future research, a further quantitative assessment on cropland quality is worth to conduct, so that the impacts of built-up land on the quality of cropland could be more explicitly addressed. Moreover, a quantitative investigation on the driving forces of the conversion from cropland to built-up land will be more helpful on framing cropland-related policies.

\section{Acknowledgements}

All the authors are grateful to Professor Keith. C. Clarke for his valuable comments on an earlier version of the paper. The comments from the reviewers have been greatly helpful for strengthening the arguments of the paper.

\section{References}

Anderson K, Peng C Y, 1998. Feeding and fueling China in the 21st century. World Development, 26(8): $1413-1429$.

Boland A, 2000. Feeding fears: Competing discourses of interdependency, sovereignty, and China's food security. Political Geography, 19: 55-76.

Cai Y L, Fu Z Q, Dai E F, 2002. The minimum areas per capita of cultivated land and its implication for the optimization of land resources allocation. Acta Geographica Sinica, 57(2): 127-134. (in Chinese)

d'Amour C B, Reitsma F, Baiocchi G et al., 2017. Future urban land expansion and implications for global croplands. Proceedings of the National Academy of Sciences, 114(34): 8939-8944.

Deng X, Huang J, Rozelle S et al., 2006. Cultivated land conversion and potential agricultural productivity in China. Land Use Policy, 23(4): 372-384.

Deng X, Huang J, Rozelle S et al., 2015. Impact of urbanization on cultivated land changes in China. Land Use 
Policy, 45: 1-7.

Ding C, 2003. Land policy reform in China: Assessment and prospects. Land Use Policy, 20: 109-120.

Jiang X C, 2003. Urbanization in China on WTO backgrounds. Urban Studies, 10(5): 23-34. (in Chinese)

Jiao J, Wang J, Jin F et al., 2016. Understanding relationship between accessibility and economic growth: A case study from China (1990-2010). Chinese Geographical Science, 26(6): 803-816.

Li G, Fang C, Qiu D et al., 2014. Impact of farmer households' livelihood assets on their options of economic compensation patterns for cultivated land protection. Journal of Geographical Sciences, 24(2): 331-348.

Li Y, Li Y, Westlund $\mathrm{H}$ et al., 2015. Urban-rural transformation in relation to cultivated land conversion in China: Implications for optimizing land use and balanced regional development. Land Use Policy, 47: $218-224$.

Liu J, Liu M, Tian H et al., 2005. Spatial and temporal patterns of China's cropland during 1990-2000: An analysis based on Landsat TM data. Remote Sensing of Environment, 98(4): 442-456.

Liu L, Xu X, Liu J et al., 2015. Impact of farmland changes on production potential in China during 1990-2010. Journal of Geographical Sciences, 25(1): 19-34.

Liu Y S, Wang J Y, Long H L, 2010. Analysis of arable land loss and its impact on rural sustainability in southern Jiangsu Province of China. Journal of Environmental Management, 91(3): 646-653.

Long H, Liu Y, Wu X et al., 2009. Spatio-temporal dynamic patterns of farmland and rural settlements in $\mathrm{Su}-\mathrm{Xi}-\mathrm{Chang}$ region: Implications for building a new countryside in coastal China. Land Use Policy, 26(2): $322-333$.

Longley P A, 2002. Geography: Will development in urban remote sensing and GIS lead to better urban geography? Progress in Human Geography, 26(2): 231-239.

Ministry of Construction of China (MCC), 1993. Village/Small-Town Planning Standards (GB 50188-93). Beijing: Ministry of Construction of P. R. China. (in Chinese)

National Bureau of Statistics of China (NBSC), 2011. China Statistical Yearbook. Beijing: China Statistics Press. (in Chinese)

Nationwide Committee of Agricultural Regionalization (NCAR), 1981. The Comprehensive Agricultural Regionalization of China. Beijing: Agriculture Press. (in Chinese)

Pacione M, 2001. The internal structure of cities in the third world. Geography, 86(3): 189-209.

Pandey B, Seto K C, 2015. Urbanization and agricultural land loss in India: Comparing satellite estimates with census data. Journal of Environmental Management, 148: 53-66.

Qin H, 2010. Rural-to-urban labor migration, household livelihoods, and the rural environment in Chongqing Municipality, Southwest China. Human Ecology, 38(5): 675-690.

She L M, Xie B G, 2000. Some considerations about the dynamic balance of the total cultivated land quantity in China. Research of Agricultural Modernization, 21(2): 87-90. (in Chinese)

Seto K C, Fragkias M, Güneralp B et al., 2011. A meta-analysis of global urban land expansion. PLoS One, 6(8): e23777.

Tan M, Li X, Xie H et al., 2005. Urban land expansion and arable land loss in China: A case study of Beijing-Tianjin-Hebei region. Land Use Policy, 22(3): 187-196.

Tania D M, Lopez T, Aide M et al., 2001. Urban expansion and the losses of prime agricultural lands in Putero Rico. Ambio, 30: 49-54.

Tu S, Long H, 2017. Rural restructuring in China: Theory, approaches and research prospect. Journal of Geographical Sciences, 27(10): 1169-1184.

Wang Y, Scott S, 2008. Illegal farmland conversion in China's urban periphery: Local regime and national transitions. Urban Geography, 29(4): 327-347.

Xie J, Jin X, Lin Y et al., 2017. Quantitative estimation and spatial reconstruction of urban and rural construction land in Jiangsu Province, 1820-1985. Journal of Geographical Sciences, 27(10): 1185-1208.

Yang H, Li X B, 2000. Cultivated land and food supply in China. Land Use Policy, 17: 73-88.

Yeh A G O, Li X, 1999. Economic development and agricultural land loss in the Pearl River Delta, China. Habitat International, 23(3): 373-390.

Zhang Z, Wang X, Zhao X et al., 2014. A 2010 update of national land use/cover database of China at 1:100000 scale using medium spatial resolution satellite images. Remote Sensing of Environment, 149: 142-154.

Zuo L, Zhang Z, Zhao X et al., 2014. Multitemporal analysis of cropland transition in a climate-sensitive area: A case study of the arid and semiarid region of northwest China. Regional Environmental Change, 14(1): 75-89. 